\title{
One-year prevalence and the impact of migraine and tension-type headache in Turkey: a nationwide home-based study in adults
}

\author{
Mustafa Ertas • Betul Baykan • Elif Kocasoy Orhan • \\ Mehmet Zarifoglu $\cdot$ Necdet Karli $\cdot$ Sabahattin Saip • \\ Ayse Emel Onal $\cdot$ Aksel Siva
}

Received: 10 November 2011 / Accepted: 28 December 2011/Published online: 14 January 2012

(C) The Author(s) 2012. This article is published with open access at Springerlink.com

\begin{abstract}
Several studies have shown that the prevalence of migraine and tension-type headache (TTH) varied between different geographical regions. Therefore, there is a need of a nationwide prevalence study for headache in our country, located between Asia and Europe. This nationwide study was designed to estimate the 1-year prevalence of migraine and TTH and analyse the clinical features, the impact as well as the demographic and socio-economic characteristics of the participant households in Turkey. We planned to investigate 6,000 representative households in 21 cities of Turkey; and a total of 5,323 households (response
\end{abstract}

Electronic supplementary material The online version of this article (doi:10.1007/s10194-011-0414-5) contains supplementary material, which is available to authorized users.

\section{Ertas}

Department of Neurology, Anadolu Health Center Hospital, Kocaeli, Turkey

M. Ertas · B. Baykan · E. Kocasoy Orhan

Department of Neurology, Istanbul Faculty of Medicine, Istanbul University, Istanbul, Turkey

M. Ertas $(\square)$

Anadolu Saglik Merkezi Hastanesi, Noroloji Klinigi,

Cayirova, Kocaeli, Turkey

e-mail: drmustafaertas@gmail.com

M. Zarifoglu $\cdot$ N. Karli

Department of Neurology, Faculty of Medicine,

Uludag University, Bursa, Turkey

S. Saip · A. Siva

Department of Neurology, Cerrahpasa Faculty of Medicine, Istanbul University, Istanbul, Turkey

A. E. Onal

Department of Public Health, Istanbul Faculty of Medicine, Istanbul University, Istanbul, Turkey rate of $89 \%$ ) aged between 18 and 65 years were examined for headache by 33 trained physicians at home on the basis of the diagnostic criteria of the second edition of the International Classification of Headache Disorders (ICHD-II). The electronically registered questionnaire was based on the headache features, the associated symptoms, demographic and socio-economic situation and history. Of 5,323 participants (48.8\% women; mean age $35.9 \pm 12$ years) $44.6 \%$ reported recurrent headaches during the last 1 year and 871 were diagnosed with migraine at a prevalence rate of $16.4 \%$ ( $8.5 \%$ in men and $24.6 \%$ in women), whereas only 270 were diagnosed with TTH at a prevalence rate of $5.1 \%$ (5.7\% in men and $4.5 \%$ in women). The 1-year prevalence of probable migraine was $12.4 \%$ and probable TTH was $9.5 \%$ additionally. The rate of migraine with aura among migraineurs was $21.5 \%$. The prevalence of migraine was highest among 35-40-year-old women while there were no differences in age groups among men and in TTH overall. More than $2 / 3$ of migraineurs had ever consulted a physician whereas only $1 / 3$ of patients with TTH had ever consulted a physician. For women, the migraine prevalence was higher among the ones with a lower income, while among men, it did not show any change by income. Migraine prevalence was lower in those with a lower educational status compared to those with a high educational status. Chronic daily headache was present in $3.3 \%$ and the prevalence of medication overuse headache was $2.1 \%$ in our population. There was an important impact of migraine with a monthly frequency of $5.9 \pm 6$, and an attack duration of $35.1 \pm 72 \mathrm{~h}$, but only $4.9 \%$ were on prophylactic treatment. The one-year prevalence of migraine estimated as $16.4 \%$ was similar or even higher than worldwide reported migraine prevalence figures and identical to a previous nation-wide study conducted in 1998, whereas the TTH prevalence was much lower using the same methodology with the ICHD-II criteria. 
Keywords Prevalence of migraine - Prevalence of tension-type headache - Migraine $\cdot$ Tension-type headache Headache

$\begin{array}{ll}\text { Abbreviations } \\ \text { TTH } & \begin{array}{l}\text { Tension-type Headache } \\ \text { IHS }\end{array} \\ \text { International Headache Society } \\ \text { ICHD-I } & \begin{array}{l}\text { First edition of the International Classification } \\ \text { of Headache Disorders }\end{array} \\ \text { ICHD-II } & \begin{array}{l}\text { Second edition of the International } \\ \text { Classification of Headache Disorders }\end{array}\end{array}$

\section{Introduction}

Prevalence estimates of migraine as well as tension-type headache (TTH) show worldwide variations mainly due to the differences in the definitions and methodologies of the studies. It is remarkable, however, that the recent population-based studies in adults, all using the diagnostic criteria of the International Headache Society (IHS), have achieved similar prevalence rates of migraine. Several European [1-6] and American studies [7-9] have reported somewhat congruent prevalence figures about $10-12 \%$ for migraine in adults, $6 \%$ among men and $15-18 \%$ among women. A metaanalysis indicated that the prevalence of headache and migraine varied between different geographical regions, being somewhat lower in Europe than in North America but higher than in Asia and Africa [10]. So, there is a need for independent prevalence studies of migraine in different regions of the world using the IHS criteria.

The prevalence of TTH varied much more widely among studies, and more attention has been drawn to its importance during the last years. Even though TTH was known to be the most prevalent type of headache across all age groups worldwide [11, 12], there were still relatively few epidemiological studies on TTH. Authors reported that it was a paradox that the prevalence of TTH seemed higher than that of headache in general in the European studies [6]. Therefore, there is a second need for epidemiological studies investigating the TTH prevalence by strictly using the IHS criteria.

Although there were a few local epidemiological studies on headache [13-16] in our country located between Asia and Europe, published nationwide studies assessing the headache in adults are lacking. In a preliminary nationwide population-based headache survey in Turkey conducted in 1998 using the criteria of first edition of the International Classification of Headache Disorders (ICHD-I, 1988) [17], migraine prevalence was estimated to be $16.4 \%$ and TTH $31.7 \%$ among 2,007 households aged between 15 and 55 years [18].
We aimed to investigate the nationwide migraine and TTH prevalence and analyse the clinical features as well as the demographic and socio-economic characteristics using the second edition of the ICHD (ICHD-II, 2004) criteria [19] for the first time in a large sample using a populationbased design in Turkey.

\section{Methods}

We designed a nationwide, community- based prevalence study in adults aged between 18 and 65 years, with face-toface interviews by 33 specially trained general practitioner physicians using a structured electronic questionnaire. The comprehensive interview form included diagnostic questions based on the ICHD-II criteria [19] and revised criteria for chronic migraine and medication overuse headache $(\mathrm{MOH})$ [20] for diagnoses of migraine, TTH and $\mathrm{MOH}$ within the last 1 year, questions about features of headache and associated symptoms, demographic and socio-economic conditions of the participants, information about the previous physician visits, previous diagnoses, disability assessment by Turkish version of MIDAS questionnaire [21], acute and prophylactic medication in migraineurs. TTH was diagnosed if the participants were not diagnosed with "definite" or "probable" migraine and fulfilled all TTH criteria.

We used a multi-stage sampling strategy, which involved as the initial stage, the selection of 21 cities representative of the characteristics of households in all 7 geographical regions of Turkey based on the ratio of their population to the total population of Turkey as reported in the year of 2008 by the Turkish Statistical Institute (http://rapor.tuik.gov.tr/reports/rwservlet?adnksdb2=\& ENVID=adnksdb2Env\&report=turkiye_yasgr.RDF\&p_ yil=2008\&p_dil=1\&desformat=html). Six of the seven geographical regions of Turkey were each represented by three different cities and only one last smallest region was investigated by two representative cities. As the largest city of Turkey with a high internal migration rate, Istanbul was considered as a different region and represented by 1,400 households. In the second part of selection, the distribution of urban and rural populations, gender and age groups were all taken into account to choose the target population in these cities, to ensure that there will be no selection bias. The total population of Turkey with an age range of 18-65 years which was around 40 million was represented by 6,000 households with an acceptable error rate of $\pm 1.3 \%$. After establishing the total number of households to be interviewed (for example $n=240$ households for the city of A), this number was further divided by the urban and rural populations of this specific city. By the guidance of the quotas for each city, the houses to be visited were determined using a simple random-sampling method in 
districts, streets and rural areas. Only one person was interviewed in each household to avoid any bias. A Kish sampling grid was used to select one person per household to be interviewed. A total of 6,000 households were visited. After excluding the households visited but not interviewed because of several reasons such as ("rejecting to be interviewed", "having no time", "non-presence at home" etc.), $89 \%$ of the households had valid interviews. At the end, the statistical standard error was $\pm 1.3 \%$ within $95 \%$ confidence interval for 5,323 interviews, as planned.

The study was completed within 3 months in the year of 2008. Each of the 33 physicians visited 1-3 cities and each city was visited by $1-10$ physicians. In every visited home, a physician accompanied by an interviewer administered the questionnaire using an electronic palm device connected to study-headquarters by mobile phone card to transfer the data online.

The role of the physician was to exclude secondary headaches and medical conditions interfering with the primary headache disorders, by examining the patients and reviewing their related investigations such as MRIs, LP records, sinus radiographs, etc. were available. They interviewed the participants about the previous physician visits related to headache in detail, discussed about the diagnoses established and reviewed all the available medical reports. For example if a participant reported that he had the diagnosis of sinusitis, the history about acute and chronic presentations and temporal relationship with headache attacks were ascertained after viewing the radiographs.

The headache diagnosis was based on the answers of the questionnaire, according to the ICHD-II criteria. We used the 1-year prevalence figures, indicating the proportion of the population that had an active disease, which was more relevant than the lifetime prevalence, which was considered less reliable due to recall problems. The age groups below 18 years (children) and over 65 years (elderly) were not included in investigation of the prevalence rate in adults.

The questionnaire assessed the headache features, diagnosis, headache related impact, demographics, and disability assessed by the Turkish version of MIDAS questionnaire. The participants were asked to provide the mean number of attacks and mean number of days with headache per month during the last year and the untreated duration of attack in hours. Aura was described as the recurrent symptoms starting before or just with the start of the headache lasting $5 \mathrm{~min}$ to $1 \mathrm{~h}$. Five types of aura namely: visual (hemianopia and flashing lights) somatosensory, speech disturbances, vertigo/dizziness and motor dysfunction were questioned separately.

Descriptive statistics were applied and Chi-square test, $t$ test and logistic regression test were used for the group comparisons, where appropriate. We used the SPSS 15 software.

\section{Results}

A total of 5,323 participants (2,600 women and 2,723 men) were reviewed. Of the study population, $82.8 \%$ are city dwellers, $16.4 \%$ are borough dwellers and $0.8 \%$ are village dwellers. The ages of participants ranged between 18 and 65 years with a mean of $36.2 \pm 12$ years for women and $35.7 \pm 12$ years for men. These distributions of participants are comparable to the demographics of Turkey as reported in the year of 2008 by the Turkish Statistical Institute.

Migraine prevalence

2,376 (44.6\%) participants reported recurrent headaches within the last 1 year, whereas 2,947 were free of recurrent headaches. Of these 2,376 participants with headache, $1,373(57.8 \%)$ were women and $1,003(42.2 \%)$ were men. Of the total study population, 871 were diagnosed with "definite" migraine and the 1-year prevalence of migraine was estimated to be $16.4 \%$. The details of prevalence of definite and probable migraine diagnosed based on the ICHD-II criteria by gender are shown in Table 1 . The rate for migraine with aura among migraineurs is $21.5 \%$. The prevalence of migraine is highest among 35-40-year-old women while there is seemingly no such great difference in age groups among men (Fig. 1).

\section{TTH prevalence}

After excluding the participants who were diagnosed with "definite" or "probable" migraine, 270 of the remaining were diagnosed with "definite" TTH according to the ICHD-II criteria and the 1-year prevalence of "definite" TTH was estimated to be $5.1 \%$. All details of the TTH

Table 1 The prevalence of migraine types according to gender in Turkey

\begin{tabular}{|c|c|c|c|}
\hline & $\begin{array}{l}\text { Women, } \\
n=2,600 \\
(\%)\end{array}$ & $\begin{array}{l}\text { Men, } \\
n=2,723 \\
(\%)\end{array}$ & $\begin{array}{l}\text { Total, } \\
n=5,323 \\
(\%)\end{array}$ \\
\hline Definite migraine & $640(24.6)$ & $231(8.5)$ & $871(16.4)$ \\
\hline Probable migraine & $349(13.4)$ & $313(11.5)$ & $662(12.4)$ \\
\hline Migraine with aura & $135(5.2)$ & $52(1.9)$ & $187(3.5)$ \\
\hline $\begin{array}{l}\text { Probable migraine with } \\
\text { aura }\end{array}$ & $42(1.6)$ & $45(1.7)$ & 87 (1.6) \\
\hline Chronic migraine & $17(0.7)$ & $6(0.2)$ & $23(0.4)$ \\
\hline $\begin{array}{l}\text { Probable chronic migraine } \\
\text { (with medication } \\
\text { overuse) }\end{array}$ & $56(2.2)$ & $15(0.6)$ & $71(1.3)$ \\
\hline $\begin{array}{l}\text { Total migraine } \\
(\text { definite }+ \text { probable })\end{array}$ & $989(38.0)$ & $544(20.0)$ & $1,533(28.8)$ \\
\hline
\end{tabular}


Table 2 The prevalence of tension-type headache (TTH) types according to gender in Turkey

\begin{tabular}{lccc}
\hline & $\begin{array}{l}\text { Women, } \\
n=2,600 \\
(\%)\end{array}$ & $\begin{array}{l}\text { Men, } \\
n=2,723 \\
(\%)\end{array}$ & $\begin{array}{l}\text { Total, } \\
n=5,323 \\
(\%)\end{array}$ \\
\hline Definite TTH & $116(4.5)$ & $154(5.7)$ & $270(5.1)$ \\
Rare episodic & $81(3.1)$ & $94(3.4)$ & $175(3.3)$ \\
Frequent episodic & $34(1.3)$ & $50(1.8)$ & $84(1.6)$ \\
Chronic & $1(0.04)$ & $10(0.4)$ & $11(0.2)$ \\
Probable TTH & $228(8.8)$ & $276(10.1)$ & $504(9.5)$ \\
Rare episodic & $157(6.0)$ & $213(7.8)$ & $370(6.9)$ \\
Frequent episodic & $66(2.5)$ & $52(1.9)$ & $118(2.2)$ \\
Chronic & $5(0.2)$ & $11(0.4)$ & $16(0.3)$ \\
Total TTH & $344(13.2)$ & $430(15.8)$ & $774(14.5)$ \\
(definite + probable) & & & \\
\hline
\end{tabular}

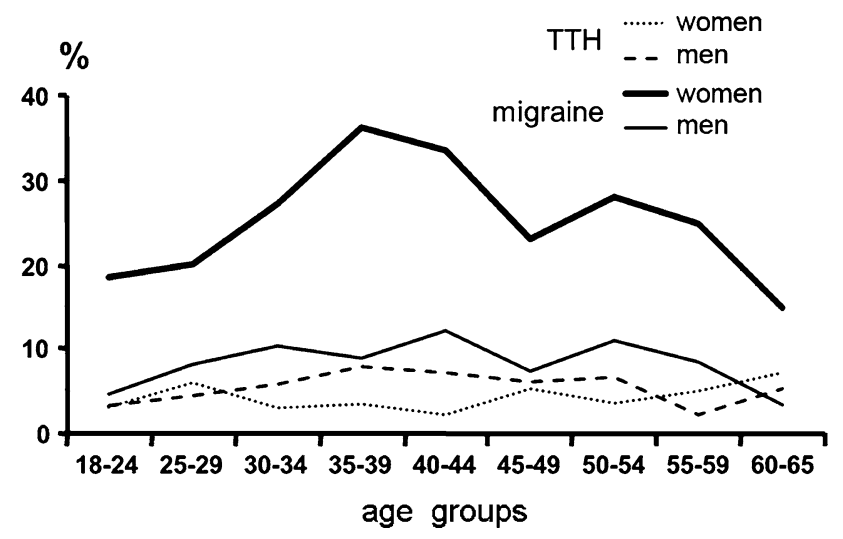

Fig. 1 Migraine and tension-type headache prevalence in age groups in relation to gender

prevalence regarding rare episodic, frequent episodic and chronic TTH by gender are presented in Table 2. Figure 1 also shows the percentage of the patients with TTH within the age groups of the study population, which did not show any significant difference by gender.

\section{Unclassified headache}

Total 69 patients (1.3\% of study population) had reported other types of recurrent headaches not diagnosed as definite or probable migraine or TTH. Of these 69 patients with unclassified headache, $64(1.2 \%)$ had episodic headache and 5 (0.09) had chronic headache.

Physician consults and headache diagnoses

The analysis of physician consults for headaches revealed that more than two-thirds $(70.6 \%)$ of migraineurs had consulted a physician, whereas only one-third of the TTH patients had a physician visit, with a significant difference between the headache groups. Mostly consulted physicians were neurologists as seen in Fig. 2. Previous headache diagnoses of patients with migraine and TTH are outlined in Table 3. In the analysis of migraineurs for previous diagnosis of their migraine headaches, less than half had diagnosis of migraine $(42.0 \%)$ at the first physician visit and only half of migraineurs $(51.2 \%)$ had diagnosis of migraine at the first or the following visits. Misdiagnoses included TTH (or psychogenic headache), sinusitis, hypertension, cervicogenic headache, and headache due to vision problem, in order of decreasing frequency. One-third of TTH patients were misdiagnosed with sinusitis, followed by other misdiagnoses such as hypertensive or cervicogenic headache, but definite pure TTH patients diagnosed with migraine were really rare $(1 \%)$.

Socio-economic characteristics

Tables 4 and 5 summarize certain socio-economic characteristics of the study population. Migraine prevalence is higher among unemployed for both genders and housewives. In women, migraine prevalence is higher (26.4\%) among the ones with a lower income (less than 1,300 US\$ monthly) than the ones with a higher income $(20.3 \%)$, while in men, it is the same in the ones with lower income $(8.5 \%)$ and the ones with higher income $(8.5 \%)$. There is no change in prevalence by income in patients with TTH, in both genders (Table 5). Regarding the educational status of participants, migraine prevalence is highest among illiterates $(31.6 \%)$ while it is $20.4 \%$ among participants who could read and write only without formal education, $19.1 \%$ among primary school graduates (5-year education), $14.2 \%$ among junior high school graduates (8-year education), $15.0 \%$ among high school graduates, and 14.9\% among university graduates. Thus, migraine prevalence is lower in those with a lower educational status than those with a high educational status.

Chronic daily headache and medication overuse headache

Medication overuse headache (MOH) was found in 114 (2.1\%) of the total study population according to the revised criteria of $\mathrm{MOH}$ [20], being in $8.2 \%$ of patients with migraine, whereas this figure was $1.9 \%$ among patients with pure TTH. Chronic daily headache was diagnosed in $3.3 \%$ of the study population. Prevalence rate is $1.8 \%$ for chronic migraine $(0.4 \%$ for those without medication overuse and $1.3 \%$ for those with medication overuse), and $0.2 \%$ for chronic TTH $(0.1 \%$ for those without medication overuse and $0.09 \%$ for those with 
Fig. 2 Cumulative percentage of visited physicians for headache. (For example, of 2,376 headache sufferers, $47.1 \%$ consulted neurologist)

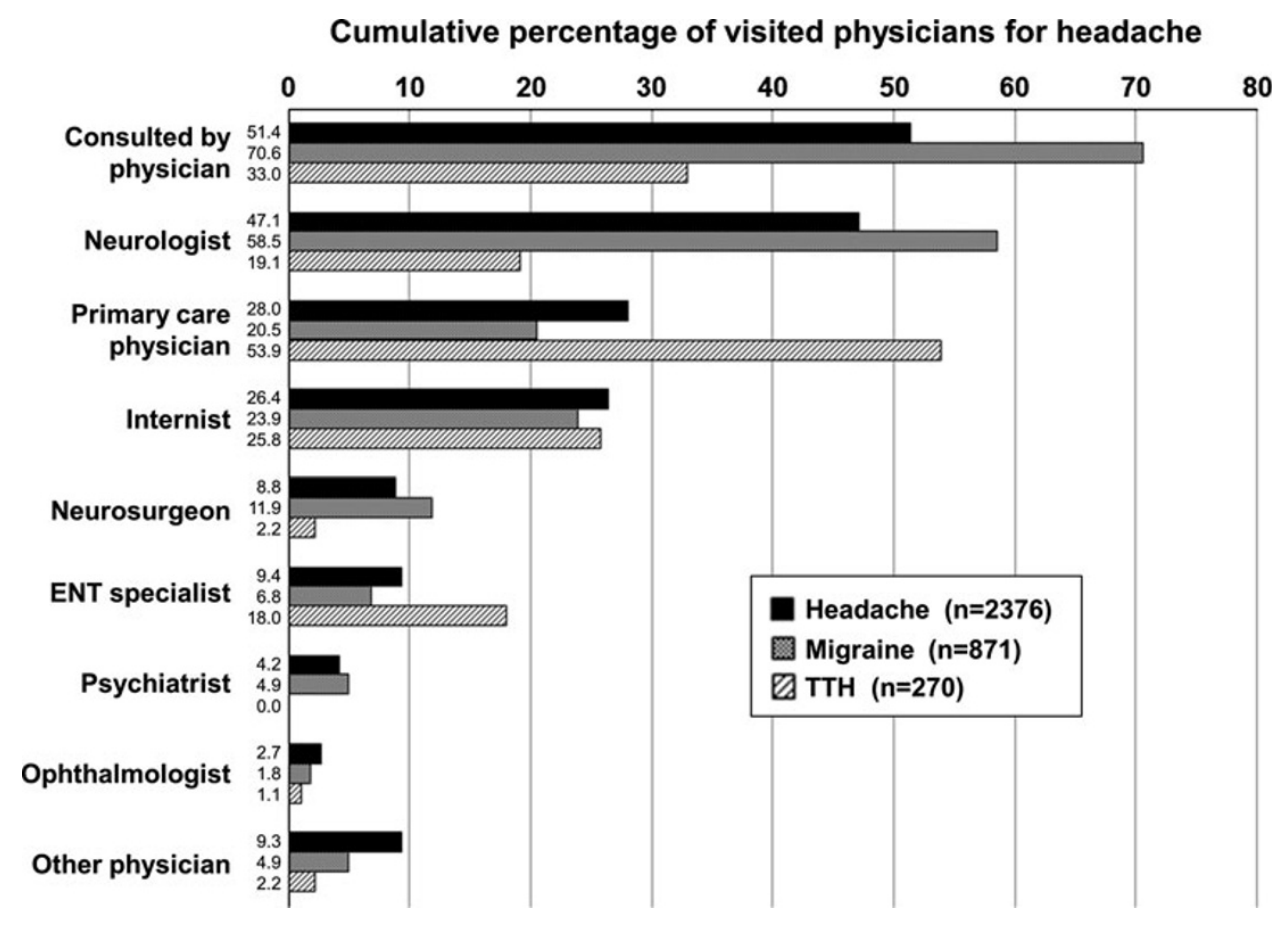

Table 3 Previous headache diagnoses of migraineurs and patients with TTH

\begin{tabular}{|c|c|c|c|c|}
\hline & \multicolumn{2}{|c|}{ Patients with definite migraine } & \multicolumn{2}{|c|}{ Patients with definite TTH } \\
\hline & $\begin{array}{l}\text { First Dx of migraine, } \\
n=615^{\mathrm{a}}(\%)\end{array}$ & $\begin{array}{l}\text { Cumulative Dx of migraine, } \\
n=615^{\mathrm{b}}(\%)\end{array}$ & $\begin{array}{l}\text { First Dx of TTHs, } \\
n=89^{\mathrm{a}}(\%)\end{array}$ & $\begin{array}{l}\text { Cumulative Dx of TTHs, } \\
n=89^{\mathrm{b}}(\%)\end{array}$ \\
\hline Migraine & 42.0 & 51.2 & 1.1 & 1.1 \\
\hline Tension/psychogenic & 22.8 & 30.1 & 33.7 & 43.8 \\
\hline Sinusitis & 15.3 & 18.9 & 37.1 & 39.3 \\
\hline Hypertension & 3.6 & 4.1 & 10.1 & 11.2 \\
\hline Cervicogenic & 2.6 & 3.9 & 5.6 & 9.0 \\
\hline Vision problem & 1.0 & 1.0 & 0.0 & 1.1 \\
\hline Other & 12.8 & 14.1 & 12.4 & 12.4 \\
\hline
\end{tabular}

Dx diagnosis, TTHs tension-type headache patients

${ }^{a}$ Diagnosis of first physician (one participant has one diagnosis)

${ }^{\mathrm{b}}$ Cumulative percentage of diagnoses made by first and other physicians (one participant might have more than one diagnosis)

medication overuse). Chronic daily headache was present in $10.9 \%$ of definite migraineurs, $7.1 \%$ of probable migraineurs and $4.1 \%$ of definite TTH patients, and $3.2 \%$ of probable TTH patients.

\section{Attack characteristics}

We further investigated the attack characteristics, disability, and the medication history in migraine sufferers by gender. Regarding the headache characteristics in migraineurs (Table 6), the average attack number was nearly 6 per month lasting nearly 1.5 days per attack. Attack durations tended to be shorter in men when compared to women and women experienced more nausea and allodynia compared to men (Table 6). More than half of the migraineurs $(54.2 \%)$ reported that their headache attacks were usually severe. Of migraineurs who never sought medical advice, $40 \%$ had severe headache whereas $60 \%$ of those who ever consulted had severe headache. Of migraineurs, 54.5\% reported headache limited to one side (persistently at one side or side-shift from attack to attack), $72.9 \%$ reported headache limited to or predominant on one side. In $27.1 \%$ of migraineurs, headache was always equal in both sides.

In the disability assessment of the migraineurs, a MIDAS score of 1 (none or minor disability due to migraine) was reported in $54.9 \%$ of migraineurs while the 
Table 4 Some socio-demographic characteristics of participants and comparison between headache types

\begin{tabular}{|c|c|c|c|c|c|c|c|c|c|}
\hline & \multicolumn{3}{|c|}{ Study group (\%) } & \multicolumn{3}{|c|}{ Migraine group (\%) } & \multicolumn{3}{|c|}{ TTH group (\%) } \\
\hline & $\begin{array}{l}\text { Women } \\
(n=2,600)\end{array}$ & $\begin{array}{l}\text { Men } \\
(n=2,723)\end{array}$ & $\begin{array}{l}\text { Total } \\
(n=5,323)\end{array}$ & $\begin{array}{l}\text { Women } \\
(n=640)\end{array}$ & $\begin{array}{l}\text { Men } \\
(n=231)\end{array}$ & $\begin{array}{l}\text { Total } \\
(n=871)\end{array}$ & $\begin{array}{l}\text { Women } \\
(n=116)\end{array}$ & $\begin{array}{l}\text { Men } \\
(n=154)\end{array}$ & $\begin{array}{l}\text { Total } \\
(n=270)\end{array}$ \\
\hline University degree & 22.8 & 23.9 & 23.4 & 19.5 & 26.8 & 21.5 & 20.7 & 25.3 & 23.3 \\
\hline Housewife/unemployed & 48.9 & 7.6 & 27.9 & 58.1 & 13.4 & 46.3 & 53.4 & 5.8 & 26.3 \\
\hline City dweller & 84.8 & 80.9 & 82.8 & 81.3 & 84.0 & 82.0 & 86.2 & 77.3 & 81.1 \\
\hline $\begin{array}{l}\text { Monthly income }<1,300 \\
\text { US\$ }\end{array}$ & 70.5 & 75.0 & 72.8 & 75.6 & 74.9 & 75.4 & 71.6 & 76.6 & 74.4 \\
\hline House owner & 66.2 & 638 & 65.0 & 61.9 & 64.9 & 62.7 & 64.7 & 59.7 & 61.9 \\
\hline
\end{tabular}

Table 5 Economical profile of participants and migraine prevalence in relation to income groups

\begin{tabular}{|c|c|c|c|c|c|c|}
\hline & \multicolumn{3}{|c|}{ Migraine prevalence $(\%)$} & \multicolumn{3}{|c|}{ TTH prevalence $(\%)$} \\
\hline & $\begin{array}{l}\text { Women } \\
(n=640 \\
\text { of } 2,600)\end{array}$ & $\begin{array}{l}\text { Men } \\
(n=231 \\
\text { of } 2,723)\end{array}$ & $\begin{array}{l}\text { Total } \\
(n=871 \\
\text { of } 5,323)\end{array}$ & $\begin{array}{l}\text { Women } \\
(n=116 \\
\text { of } 2,600)\end{array}$ & $\begin{array}{l}\text { Men } \\
(n=154 \\
\text { of } 2,723)\end{array}$ & $\begin{array}{l}\text { Total } \\
(n=270 \\
\text { of } 5,323)\end{array}$ \\
\hline \multicolumn{7}{|l|}{ Living area } \\
\hline Metropolitans & 24.1 & 8.1 & 16.2 & 4.7 & 5.6 & 5.1 \\
\hline Smaller cities or areas & 26.1 & 9.3 & 16.7 & 3.8 & 5.8 & 4.9 \\
\hline$P$ value & NS & NS & NS & NS & NS & NS \\
\hline \multicolumn{7}{|l|}{ Income (monthly) } \\
\hline$<1,300$ US\$ & 26.4 & 8.5 & 17.0 & 4.5 & 5.8 & 5.2 \\
\hline$\geq 1,300$ US\$ & 20.3 & 8.5 & 14.7 & 4.3 & 5.3 & 4.8 \\
\hline$P$ value & 0.000 & NS & 0.028 & NS & NS & NS \\
\hline
\end{tabular}

$P$ value in Chi-square test

Table 6 Attack characteristics of migraineurs

\footnotetext{
a In unpaired $t$ test

${ }^{b}$ In Chi-square test

c In logistic regression test

${ }^{\mathrm{d}}$ Mean \pm SD
}

\begin{tabular}{lllll}
\hline & Women & Men & $P$ value & Total \\
\hline Number of attacks per month (mean \pm SD) & $6.0 \pm 6^{\mathrm{d}}$ & $5.7 \pm 6$ & $\mathrm{NS}^{\mathrm{a}}$ & $5.9 \pm 6$ \\
Attack duration in hours & $39.2 \pm 78$ & $24.0 \pm 49$ & $0.002^{\mathrm{a}}$ & $35.1 \pm 72$ \\
(mean \pm SD) & & & \\
Headache days per month & $6.3 \pm 6$ & $6.0 \pm 6$ & $\mathrm{NS}^{\mathrm{a}}$ & $6.2 \pm 6$ \\
(mean \pm SD) & & & \\
$\geq 15$ headache days per month (\%) & 11.4 & 9.5 & $\mathrm{NS}^{\mathrm{b}}$ & 10.9 \\
Headache severity (\%) & & & \\
$\quad$ Usually mild & 5.8 & 9.5 & $\mathrm{NS}^{\mathrm{c}}$ & 6.8 \\
$\quad$ Usually moderate & 39.8 & 36.8 & & 39.0 \\
$\quad$ Usually severe & 54.4 & 53.7 & & 54.2 \\
Limited to one side & $52.2^{\mathrm{d}}$ & 61.0 & $0.012^{\mathrm{b}}$ & 54.5 \\
Throbbing & 83.4 & 76.6 & $0.015^{\mathrm{b}}$ & 81.6 \\
Increase with activity & 93.8 & 92.6 & $\mathrm{NS}^{\mathrm{b}}$ & 93.5 \\
With nausea or vomiting & 84.4 & 71.0 & $0.000^{\mathrm{b}}$ & 80.8 \\
With photophobia & 82.7 & 82.3 & $\mathrm{NS}^{\mathrm{b}}$ & 82.5 \\
With phonophobia & 85.8 & 83.5 & $\mathrm{NS}^{\mathrm{b}}$ & 85.2 \\
With photo- and phonophobia & 77.0 & 77.1 & $\mathrm{NS}^{\mathrm{b}}$ & 77.0 \\
With allodynia & 64.1 & 52.8 & $0.002^{\mathrm{b}}$ & 61.1 \\
\hline
\end{tabular}


score was 2 (mild disability) in $19.7 \%$, the score was 3 (moderate disability) in $15.8 \%$ and finally, the score was 4 (severe disability) in $9.5 \%$.

\section{Attack medication}

As an attack medication, $19.3 \%$ of 871 migraineurs reported the use of simple analgesics, $15.8 \%$ combined analgesics, $41.4 \%$ nonsteroidal anti-inflammatory drugs (NSAIDs), $14.5 \%$ ergots, and only $2.9 \%$ triptans. $\mathrm{MOH}$ was found in $8.2 \%$ of migraineurs $(8.8 \%$ in women and $6.5 \%$ in men). Overused medications were simple analgesics alone in $4.8 \%$ of migraineurs $(5.3 \%$ in women and $3.5 \%$ in men) or combinations of ergots, triptans and analgesics in $3.3 \%$ of migraineurs (3.4\% in women and $3.0 \%$ in men). Only in $43.1 \%$ of migraineurs, medication advice was given by physician. Chronic migraine without $\mathrm{MOH}$ was diagnosed in $2.6 \%$ of migraineurs $(2.7 \%$ in women and $2.6 \%$ in men).

Prophylactic medication

Although more than half of the migraineurs reported usually severe headache attacks and 4 or more attacks per month, only $4.9 \%$ were on prophylactic medication with mostly antidepressants $(3.9 \%$ at the time of the questionnaire). Mostly used antidepressants were selective serotonin reuptake inhibitors (SSRIs) with a current rate of $2.8 \%$ and tricyclics with $1.0 \%$. The current and past use of other prophylactic treatments such as beta blockers, flunarizin and antiepileptic drugs were less than $1 \%$ each.

\section{Discussion}

Our nationwide population-based study estimated the 1-year prevalence of definite migraine as $16.4 \%$, probable migraine as $12.4 \%$ and of pure $\mathrm{TTH}$ as $5.1 \%$, probable TTH as $9.5 \%$ with ICHD-II criteria, constituting a total of $43.4 \%$ of the general population suffering from these two primary headache types. We had planned to reach 6,000 representative households and in the end, a total of 5,323 households were examined for headache. This excellent response rate of $89 \%$ probably reflects the conductance of the study directly by physicians face-to-face rather than sending a questionnaire. The prevalence of migraine was highest among 35-40-year-old women while there were no big differences in age groups among men and in TTH overall, as shown in Fig. 1.

The striking well-known female preponderance in patients with migraine which is also evident in our study is more consistent across studies than the overall prevalence figures of migraine $[1,5,14]$. All of the studies reveal that migraine is [6] two or three times more common in females than in males. Interestingly, the rates of the present study using ICHD-II criteria for migraine in adults aged $18-65$ years $(16.4 \%)$ as well as for migraine aura $(21.5 \%$ in migraineurs) are identical with the previous largest Turkish nation-wide headache prevalence study with the participation of 2,007 households aged between 15 and 55 years [18] with the ICHD-I criteria. Some studies indicate that the prevalence of headache and especially of migraine has been increasing during the last decades in Europe [6, 22, 23]. Although our study showed no significant change in the migraine prevalence compared to the national study of 10 years ago from the present study, the male to female ratio was $1: 3$ in the present one while it was $1: 2$ in the previous one. Our study with more than the double sample size in comparison to the former one probably reflects the real gender difference. Although it is well-established that headache suffering, including migraine, was highly prevalent especially in younger women overall in the world, the differences of headache features between men and women were thoroughly investigated only in a few studies [24]. Our study showed that women had a significantly longer attack duration, more nausea and more allodynia in comparison to men among other differences as seen in Table 6. A population-based study in the UK reported the mean headache duration of $28.4 \mathrm{~h}$ in men versus $36.7 \mathrm{~h}$ in women along with non-significant changes of attack frequency and pain intensity, similar to our results [5]. Several hypotheses have been proposed to explain these differences, including fluctuations in sex hormones and receptor binding, genetic factors, differences in exposure to environmental stressors, as well as differences in response to stress and pain perception [24].

On the contrary of the small changes in the migraine prevalence around the world, the prevalence of TTH is a matter of debate and has varied widely among studies. TTH is known as the most prevalent type of headache across all age groups worldwide [11]. Nineteen studies have reported the TTH prevalence in Europe and the prevalence of current TTH among 66,000 adults was reported as $62.6 \%$, and chronic TTH (i.e. on 15 days per month) occurred in 3.3\%. Much lower figures (current TTH $15.9 \%$, chronic TTH $0.9 \%$ ) were found in the nine studies among almost 25,000 children and the youth showing the possible increase with age $[6,23]$. The largest American study with telephone surveys reported a TTH prevalence of $38.3 \%[11,25]$ and higher figures and lifetime prevalence around $80 \%$ were reported in Denmark [26]. In our study, TTH prevalence is much lower than most of the other studies, even after the inclusion of cases with probable TTH, interestingly. Rare episodic form is the most frequent form of TTH and followed by frequent episodic form and 
lastly chronic TTH is the most infrequent form in both definite and probable TTH categories, in our study.

The wide variations in the estimated prevalence of TTH can result from the methodology, case definitions, sampling procedures, possible influence of the physician/investigators and the inclusion or exclusion of cases of infrequent episodic TTH and overlap with probable migraine. We applied the ICHD-II 2004 criteria very strictly, without allowing any influence of the physician. It is also highly likely that some unknown genetic factors besides variables such as environmental risk factors or culturally determined differences in symptom reporting may further explain this discrepancy. It is important to note that in this study, TTH was a diagnosis of exclusion and it was only diagnosed in headache sufferers if definite or probable migraine were not diagnosed according to ICHD-II criteria. Hence, this could be one of the important reasons that the TTH rate in our study is not as high as the previous study in our country [18].

The difference of results between these two Turkish headache epidemiological studies can also be evaluated, considering the continuum hypothesis as a basis. The two ends of headache spectrum are TTH and migraine, both might evolve into other during time or from one attack to another. Mixed headache, so called TTH and migraine in the same individual, is accepted as the occurrence of spectrum of headache in the same individual [27]. Both adolescent and adult studies have shown that headache might evolve into both ends of spectrum [28, 29]. Thus, the low prevalence of TTH might be the evidence of evolving of TTH into probable migraine/migraine by some external or internal modifiers such as socio-economic difficulties or hormonal changes.

Another alternative conceptual approach, the "severity model" of headache, considers a continuum of headache ranging from mild to severe forms with specific headache subtypes distinguished by level of severity rather than unique constellations of symptoms [30].

Stovner and Colette [6] compared the results from the studies using different methods of data collection and reported that only for migraine and headache in general could meaningful comparisons be made; in relation to $\mathrm{TTH}$, there were too few studies available. Most questionnaire studies use somewhat modified criteria, whereas studies based on personal interviews seem to give somewhat higher prevalence than those using questionnaires. The ways the ICHD criteria are applied and the diagnoses included are also of great importance. The problem of multiple headache types occurring in the same patient may represent problems in headache epidemiologic studies. One diagnostic dilemma is the overlap between TTH and probable migraine. It is well-known in clinical practice that many patients have comorbid TTH and migraine, or in other words many migraineurs may experience headaches very similar to TTH in some of their attacks. Thus, the trend and thoughts of the physician could affect the diagnosis. Being aware of this, our study was based on the strict computerized application of ICHD-II criteria aiming to exclude the subjectivity of the conducting physicians. Furthermore, some individuals suffer from infrequent, not disturbing headaches and could not remember the exact profile. It is also known that subjects' headache symptoms might change during a given period or they might even forget that they had experienced headache [29]. All these factors pose difficulties in diagnosing headache in the population based epidemiological studies. This is particularly true for the probable headache diagnoses. Using ICHD-II criteria strictly, we showed that pure TTH is indeed rare. In ICHD-II, fulfilment of the diagnostic criteria for main groups of migraine and TTH or any of their subtypes, always trumps fulfilment of criteria for the probable diagnostic categories [19].

Although many studies investigated the prevalence of migraine and TTH in Western Europe and North America, there are only a few studies carried out in Eastern Europe. In the Republic of Georgia, an eastern neighbour of our country, one-year prevalence was estimated to be $6.5 \%$ for migraine, $9.2 \%$ for probable migraine (all migraine $15.6 \%$ ), $10.0 \%$ for TTH, $27.3 \%$ for probable TTH (all TTH $37.3 \%$ ) in a community-based door-to-door survey, conducted by four medical residents [31]. So they found a lower rate for migraine but a higher rate for TTH in comparison to our results. Another study from Croatia located also in the eastern bank of Europe reported a crude and lower prevalence of TTH as $21.2 \%$ [32]. It is interesting to note that both of these studies also showed relatively low prevalence rates of TTH, like in our study. Whether these regional differences are real or mainly a result of differences in the methodology and conduction of the studies is uncertain.

The prevalence of chronic daily headache ( $\geq 15$ headache days per month) was $3.3 \%$ in our nationwide study, similar to many studies worldwide [12, 33-36]. Interestingly, an unusually high prevalence of chronic headache with a rate of $7.6 \%$ was reported from Georgia associated with a low socioeconomic status [31], showing variability of headache disorders, even in neighbours. Another population-based study from Far East of chronic daily headache in 3,377 participants reported a prevalence of $3.2 \%$ being higher in women $(4.3 \%)$ than men $(1.9 \%)$ similar to our results [35]. A $2.1 \%$ prevalence rate for $\mathrm{MOH}$ in our total study population seems to be some higher than reported rates before [31, 35, 37-39], however, recent studies reported higher rates of $\mathrm{MOH}$ in general population as in our study [34, 40, 41]. A reason for high rate of $\mathrm{MOH}$ in our study population might be related with low rate of 
prophylactic medication use which is $4.9 \%$ among migraineurs.

Although migraine is a remarkably common cause of temporary disability worldwide, many migraine sufferers have never consulted a physician. While $47.0 \%$ of migraineurs had physician consult for their headache in 1998 [18] in Turkey, this ratio has raised to $70.6 \%$ in 10 years. Though consultation rates have increased remarkably the underlying epidemiology of migraine remains stable over a decade in our country. Thus, our data support that there is no evidence of increasing prevalence of migraine with increased awareness. On the other hand, only one-third of the TTH patients had ever consulted a physician in 2008. Mostly consulted physicians were neurologists as seen in Fig. 2. Primary care physicians, who are supposed to be the first to consult for headache, were far less than neurologists in our country, reflecting the choice of the patients. A study from United States reported that $66.1 \%$ of migraineurs $(68.1 \%$ in females and $57.3 \%$ in males) had ever consulted a physician [42]. While in this American study $61 \%$ of migraineurs who never consulted reported severe headache, in our study $40 \%$ of migraineurs who never consulted had usually severe headache. Of migraineurs who never consulted, $47.6 \%$ had 4 or more attack frequency per month, $14.1 \%$ had more than 1.5 days average attack duration and $21.5 \%$ had more than 6 headache days per month whereas of those who ever consulted, $57.4 \%$ had 4 or more attack frequency per month, $28.4 \%$ had more than 1.5 days average attack duration and $36.4 \%$ had more than 6 headache days per month. These facts reflected that there were still some patients with significant impact of migraine who did not consult for their headaches.

Prevalence studies exploring the relation between socioeconomic status (SES) and headache have shown some conflicting results. The present study revealed a negative correlation of migraine prevalence with educational status unrelated to gender and with socioeconomic status only in women. Higher prevalence with lower educational status/ lower income was reported in some other studies [1, 10, 42-44]. This contradicts the usual clinical perception that migraine is a disease of rich people. In previous studies done in Turkey, there was a positive correlation showing higher migraine prevalence with higher educational status [13, 45, 46]. These studies are possibly reflecting that people with higher income/education are far more likely to consult a physician or volunteer to participate in a study. In three very large population based studies in United States, the decline of migraine prevalence with increased income or education has been explained by "social causation hypothesis" such as "factors with low socioeconomic status increase migraine prevalence" and "social selection hypothesis" such as "migraine-related dysfunction interferes with educational and occupational functioning leading to low income and low education" [42-44]. A prospective study analysing the relation between SES and risk of headache in Norway showed that low SES was associated with increased risk of frequent and chronic headache at follow-up [47]. Interestingly, the risk of frequent and chronic headache decreased with increasing individual income, but only among men [47], showing again a gender difference of SES with migraine.

Every type of misdiagnosis is still very common both for migraine and TTH in our country as shown in Table 3. Furthermore, prophylactic medication usage was unexpectedly low $(4.9 \%)$, even though neurologists were in charge for headache care for most of the patients. These points draw attention to the need of continuing education for headache management for physicians and for public to lift the real burden. The headache lectures and courses addressed mostly secondary headaches in the medical curriculum and seemed not be sufficient for appropriate management of primary headaches, taking the overall burden in daily life into account. Moreover, the optimal visit duration of headache patients should not be short. This is one of most limiting problems of Turkish neurologists who should examine huge numbers of patients every day.

There are some strong points of our study including face-to-face assessment of headaches by a specifically trained physician group with electronic database system, a large nation-wide sample size and a random population, strict application of the ICHD-II diagnostic criteria of the IHS excluding the subjectivity of the physician's diagnosis. However, there is an unavoidable risk of the effect of the question style even with the same questions and with an electronic recording system. Due to the higher impact of migraine in clinical practice in our country [45] it is possible that the physicians are more prone to handling the migraine patients than the TTH sufferers.

In conclusion, our study showed a $16.4 \%$ prevalence rate of migraine in Turkey, and it is similar or even higher than the well-established prevalence figures of migraine worldwide. Although there are still misdiagnoses, the rate of physician consults for migraine has remarkably increased to $70.6 \%$, whereas the rate of migraineurs on prophylactic treatment is still lower than expected. Finally, the prevalence of TTH with strict application of the 2004 ICHD-II diagnostic criteria is very low in our study $(5.1 \%$ for definite TTH and $9.5 \%$ for probable TTH), a finding which could reflect some unknown genetic, cultural, environmental factors or methodological differences in the study designs.

Acknowledgments This study was supported by an unrestricted grant from Ibrahim Ethem Ulagay-Menarini Group. We thank our physician team, the interviewers, the technical team and finally all participants, who contributed value to this study. This study was conducted through the efforts of Rana Sengil and Isil Celik 
Uzuncakmak from I.E. Ulagay-Menarini Group in coordination and by the hard work of Objektif Research \& Information Services in collecting data from the field.

\section{Conflict of interest None.}

Open Access This article is distributed under the terms of the Creative Commons Attribution License which permits any use, distribution and reproduction in any medium, provided the original author(s) and source are credited.

\section{References}

1. Bigal ME, Lipton RB (2009) The epidemiology, burden, and comorbidities of migraine. Neurol Clin 27(2):321-334

2. Fernandez-de-Las-Penas C, Hernandez-Barrera V, CarrascoGarrido P, Alonso-Blanco C, Palacios-Cena D, Jimenez-Sanchez S et al (2010) Population-based study of migraine in Spanish adults: relation to socio-demographic factors, lifestyle and co-morbidity with other conditions. J Headache Pain 11(2):97-104

3. Hagen K, Zwart JA, Vatten L, Stovner LJ, Bovim G (2000) Prevalence of migraine and non-migrainous headache-headHUNT, a large population-based study. Cephalalgia 20(10):900906

4. Lanteri-Minet M, Valade D, Geraud G, Chautard MH, Lucas C (2005) Migraine and probable migraine-results of FRAMIG 3, a French nationwide survey carried out according to the 2004 IHS classification. Cephalalgia 25(12):1146-1158

5. Steiner TJ, Scher AI, Stewart WF, Kolodner K, Liberman J, Lipton RB (2003) The prevalence and disability burden of adult migraine in England and their relationships to age, gender and ethnicity. Cephalalgia 23(7):519-527

6. Stovner LJ, Colette A (2010) Prevalence of headache in Europe: a review for the Eurolight project. J Headache Pain 11:289-299

7. Lipton RB, Scher AI, Kolodner K, Liberman J, Steiner TJ, Stewart WF (2002) Migraine in the United States: epidemiology and patterns of health care use. Neurology 58(6):885-894

8. Lipton RB, Stewart WF (1993) Migraine in the United States: a review of epidemiology and health care use. Neurology 43(6 Suppl 3): S6-S10

9. Stewart WF, Lipton RB, Celentano DD, Reed ML (1992) Prevalence of migraine headache in the United States. Relation to age, income, race, and other sociodemographic factors. JAMA 267(1): 64-69

10. Scher AI, Stewart WF, Liberman J, Lipton RB (1998) Prevalence of frequent headache in a population sample. Headache 38(7): 497-506

11. Crystal SC, Robbins MS (2010) Epidemiology of tension-type headache. Curr Pain Headache Rep 14:449-454

12. Jensen R, Stovner LJ (2008) Epidemiology and comorbidity of headache. Lancet Neurol 7(4):354-361

13. Aygul R, Deniz O, Kocak N, Orhan A, Ulvi H (2005) The clinical properties of a migrainous population in eastern Turkey-Erzurum. South Med J 98(1):23-27

14. Celik Y, Ekuklu G, Tokuc B, Utku U (2005) Migraine prevalence and some related factors in Turkey. Headache 45(1):32-36

15. Inan LE, Tulunay FC, Guvener A, Tokgoz G, Inan N (1994) Characteristics of headache in migraine without aura and episodic tension-type headache in the Turkish population according to the IHS classification. Cephalalgia 14(2):171-173

16. Kececi H, Dener S (2002) Epidemiological and clinical characteristics of migraine in Sivas, Turkey. Headache 42(4):275-280
17. Headache Classification Committee of the International Headache Society (1988) Classification and diagnostic criteria for headache disorders, cranial neuralgias and facial pain. Headache Classification Committee of the International Headache Society. Cephalalgia 8(Suppl 7):1-96

18. Zarifoglu M, Siva A, Hayran O, THES G (1998) An epidemiological study of headache in Turkey: a nationwide survey. Neurology 50:A225

19. Headache Classification Subcommittee of the International Headache Society (2004) The International Classification of Headache Disorders: 2nd edn. Cephalalgia 24(Suppl 1):9-160

20. Headache Classification C, Olesen J, Bousser MG, Diener HC, Dodick D, First M et al (2006) New appendix criteria open for a broader concept of chronic migraine. Cephalalgia 26(6):742-746

21. Ertas M, Siva A, Dalkara T, Uzuner N, Dora B, Inan L et al (2004) Validity and reliability of the Turkish Migraine Disability Assessment (MIDAS) questionnaire. Headache 44(8):786-793

22. Linde M, Stovner LJ, Zwart JA, Hagen K (2011) Time trends in the prevalence of headache disorders. The Nord-Trondelag health studies (HUNT 2 and HUNT 3). Cephalalgia 31(5):585-596

23. Stewart WF, Linet MS, Celentano DD, Van Natta M, Ziegler D (1991) Age- and sex-specific incidence rates of migraine with and without visual aura. Am J Epidemiol 134(10):1111-1120

24. Peterlin BL, Gupta S, Ward TN, MacGregor A (2011) Sex matters: evaluating sex and gender in migraine and headache research. Headache 51(6):839-842

25. Schwartz BS, Stewart WF, Simon D, Lipton RB (1998) Epidemiology of tension type headache. JAMA 279:381-383

26. Rasmussen BK, Jensen R, Schroll M, Olesen J (1991) Epidemiology of headache in a general population: a prevalence study. J Clin Epidemiol 44:1147-1157

27. Cady RK (2007) The convergence hypothesis. Headache 47(Suppl 1):S44-S51

28. Karli N, Bican A, Zarifoglu M (2010) Course of adolescent headache: 4-year annual face-to-face follow-up study. J Headache Pain 11(4):327-334

29. Nachit-Ouinekh F, Chrysostome V, Henry P, Sourgen C, Dartigues JF, El Hasnaoui A (2005) Variability of reported headache symptoms and diagnosis of migraine at 12 months. Cephalalgia 25(2):117-123

30. Celentano DD, Stewart WF, Linet MS (1990) The relationship of headache symptoms with severity and duration of attacks. J Clin Epidemiol 43(9):983-994

31. Katsarava Z, Dzagnidze A, Kukava M, Mirvelashvili E, Djibuti M, Janelidze M et al (2009) Primary headache disorders in the Republic of Georgia: prevalence and risk factors. Neurology 73(21):1796-1803

32. Vukovic V, Plavec D, Pavelin S, Janculjak D, Ivankovic M, Demarin V (2010) Prevalence of migraine, probable migraine and tension-type headache in the Croatian population. Neuroepidemiology 35:59-65

33. Lanteri-Minet M, Auray JP, El Hasnaoui A, Dartigues JF, Duru G, Henry P et al (2003) Prevalence and description of chronic daily headache in the general population in France. Pain 102(1-2): 143-149

34. Jonsson P, Hedenrud T, Linde M (2011) Epidemiology of medication overuse headache in the general Swedish population. Cephalalgia 31(9):1015-1022

35. Lu SR, Fuh JL, Chen WT, Juang KD, Wang SJ (2001) Chronic daily headache in Taipei, Taiwan: prevalence, follow-up and outcome predictors. Cephalalgia 21(10):980-986

36. Wiendels NJ, Knuistingh Neven A, Rosendaal FR, Spinhoven P, Zitman FG, Assendelft WJ et al (2006) Chronic frequent headache in the general population: prevalence and associated factors. Cephalalgia 26(12):1434-1442 
37. Castillo J, Munoz P, Guitera V, Pascual J (1999) Kaplan Award 1998. Epidemiology of chronic daily headache in the general population. Headache 39(3):190-196

38. Colas R, Munoz P, Temprano R, Gomez C, Pascual J (2004) Chronic daily headache with analgesic overuse: epidemiology and impact on quality of life. Neurology 62(8):1338-1342

39. Pascual J, Colas R, Castillo J (2001) Epidemiology of chronic daily headache. Curr Pain Headache Rep 5(6):529-536

40. Aaseth K, Grande RB, Lundqvist C, Russell MB (2009) What is chronic headache in the general population? The Akershus study of chronic headache. Acta Neurol Scand Suppl 189:30-32

41. Katsarava Z, Diener HC (2008) Medication overuse headache in Germany. Cephalalgia 28(11):1221-1222

42. Lipton RB, Stewart WF, Simon D (1998) Medical consultation for migraine: results from the American Migraine Study. Headache 38(2):87-96
43. Lipton RB, Bigal ME, Diamond M, Freitag F, Reed ML, Stewart WF (2007) Migraine prevalence, disease burden, and the need for preventive therapy. Neurology 68(5):343-349

44. Lipton RB, Diamond S, Reed M, Diamond ML, Stewart WF (2001) Migraine diagnosis and treatment: results from the American Migraine Study II. Headache 41(7):638-645

45. Baykan B, Ertas M, Karli N, Akat-Aktas S, Uzunkaya O, Zarifoglu $M$ et al (2007) The burden of headache in neurology outpatient clinics in Turkey. Pain Pract 7(4):313-323

46. Koseoglu E, Nacar M, Talaslioglu A, Cetinkaya F (2003) Epidemiological and clinical characteristics of migraine and tension type headache in 1146 females in Kayseri. Turkey. Cephalalgia 23(5):381-388

47. Hagen K, Vatten L, Stovner LJ, Zwart JA, Krokstad S, Bovim G (2002) Low socio-economic status is associated with increased risk of frequent headache: a prospective study of 22718 adults in Norway. Cephalalgia 22(8):672-679 